\title{
THEIR STORIES MATTER: UNDERSTANDING THE EXPERIENCES OF SPOUSAL ABUSE AMONG GHANAIAN WOMEN IN TORONTO, CANADA
}

by

\section{Stephanie Asare}

Bachelor of Arts (Honours), University of Ontario Institute of Technology, 2015

\author{
A Major Research Paper \\ presented to Ryerson University
}

in partial fulfillment of the requirements for the degree of

\author{
Master of Arts \\ in the program of \\ Immigration and Settlement Studies
}

Toronto, Ontario, Canada, 2018

C) Stephanie Asare 2018 


\section{AUTHOR'S DECLARATION FOR ELECTRONIC SUBMISSION OF A MAJOR RESEARCH PAPER (MRP)}

I hereby declare that I am the sole author of this Major Research Paper. This is a true copy of the $\mathrm{MRP}$, including any required final revisions, as accepted by my examiners.

I authorize Ryerson University to lend this MRP to other institutions or individuals for the purpose of scholarly research.

I further authorize Ryerson University to reproduce this MRP by photocopying or by other means, in total or in part, at the request of other institutions or individuals for the purpose of scholarly research.

I understand that my MRP may be made electronically available to the public.

Stephanie Asare 


\title{
THEIR STORIES MATTER: UNDERSTANDING THE EXPERIENCES OF SPOUSAL ABUSE AMONG GHANAIAN WOMEN IN TORONTO, CANADA
}

\author{
Stephanie Asare \\ Master of Arts, 2018 \\ Immigration and Settlement Studies \\ Ryerson University
}

\begin{abstract}
The issue of spousal abuse among immigrant women in Toronto and the silence surrounding it is important to address because it is a problem that is often trivialized. This qualitative study involves semi-structured interviews with 10 intergenerational Ghanaian women living in the Greater Toronto Area who have been affected by spousal abuse. The interviews focused on their experiences, coping strategies, and the resources that helped or could have been helpful in their healing process. The study results indicate that there is a connection between spousal abuse and the development of depression, which confirms the findings from previous literature on spousal abuse. In addition, the study results also reveal that the lack of accessible information abroad was a barrier towards seeking help. Recommendations that may help Ghanaian women living in the Greater Toronto Area seek and utilize formal support and counselling services are presented.
\end{abstract}

Key words: Access to services, Ghanaian women, mental health, resilience, spousal abuse 


\section{ACKNOWLEDGMENTS}

I would like to thank my supervisor, Dr. Sepali Guruge for her guidance and support during every step of my research. Her advice and detailed feedback has been tremendously helpful in being able to complete this Major Research Paper. I would also like to thank my second reader, Dr. Sutama Ghosh for her insight and constructive feedback.

This paper would be non-existent without the 10 women who consented to participate in my study. I sincerely appreciate each person for not only sharing her time, experiences, and feelings, but also for the trust that was placed in me.

Finally and most importantly to my parents, Veronica and Nathan: Completing this entire journey would not have been possible if it were not for your support, patience, and unwavering encouragement. The gratitude I have for you believing in me and for the sacrifices you have made, is indescribable. From the bottom of my heart, thank you! 


\section{TABLE OF CONTENTS}

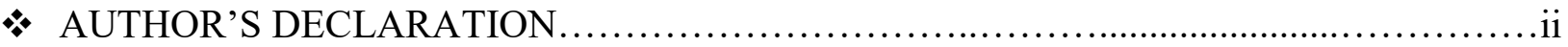

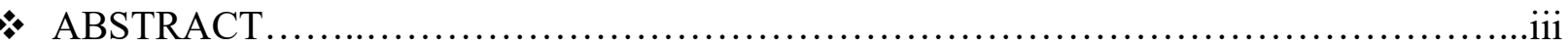

* ACKNOWLEDGEMENTS .......................................................... iv

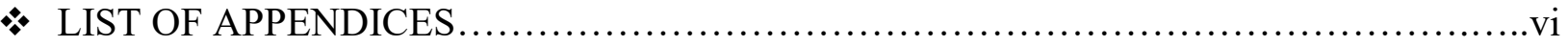

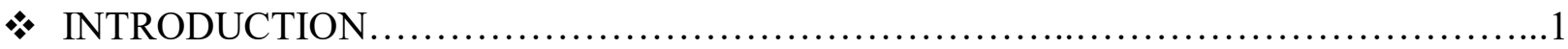

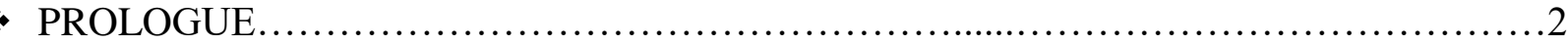

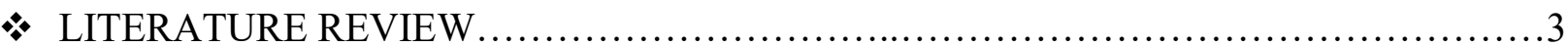

* HISTORICAL CONTEXT OF GHANAIAN IMMIGRATION TO CANADA..............6

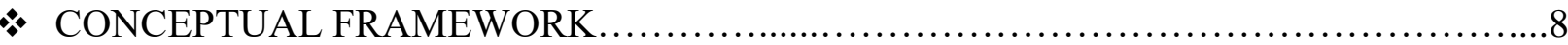

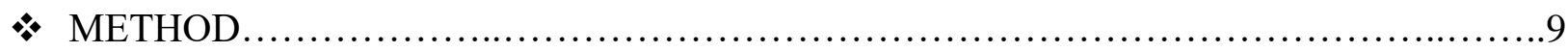

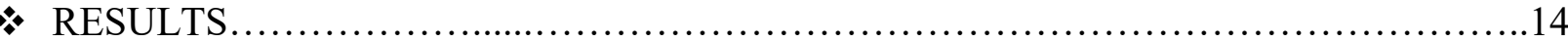

* LiMitations OF THE STUDY .................................................... 19

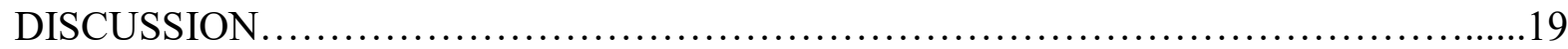

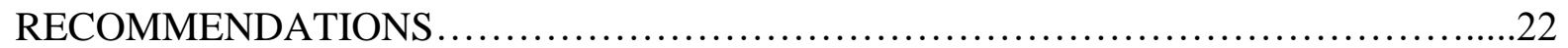

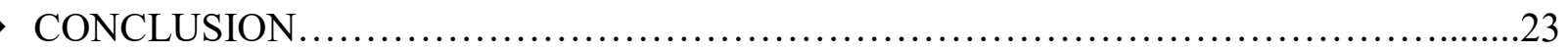

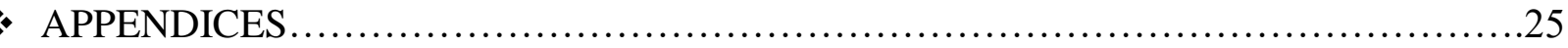

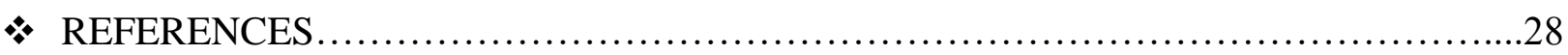




\section{LIST OF APPENDICES}

* Appendix A (Table 1.1): Sample Demographics.....................................25

* Appendix B (Table 1.2): Sample Demographics..................................26

* Appendix C (Table 1.3): Sample Demographics................................27 


\section{Introduction}

As the most prevalent form of violence against women (The World Bank, 2017), spousal abuse is pervasive, widespread and often a hidden reality in Canadian society, particularly for immigrant, ethnic minority women. Traditionally, Ghanaian people view spousal abuse as a family matter, for this reason they tend to resolve family issues within their home and not seek assistance or support from a third party (Immigration and Refugee Board of Canada, 2010 as cited in Selby, 2009; Baafi, 2010). The culture of silence contributes to the perpetuation of violence against women. This also increases the difficulty for Ghanaian immigrant women to vocalize their experiences of abuse and seek formal support when they experience spousal abuse in Canada. Given these challenges of help-seeking among women of Ghanaian origin in the Greater Toronto Area (GTA), it is important that the service sector understands what can be done to help Ghanaian women living in the GTA to seek and utilize formal support and counselling services.

In the following section I write about what influenced my interest for this research topic. After that, a review of the literature related to this subject matter is discussed, followed by the historical context of Ghanaian immigration to Canada. Next, the concept of resilience is used as a framework to understand women coping with spousal abuse. Subsequently, the study method is described, which is followed by the results of the study, the limitations, a discussion, and recommendations. Throughout this paper, I will refer to my study participants as women who have experienced spousal abuse, in order to avoid labelling the women as victims or survivors. 


\section{Prologue}

The following recounts a story which communicates my personal connection to the research topic and the influence it has on the importance of conducting a study aimed at understanding the experiences of spousal abuse, and the coping strategies of Ghanaian women in the Greater Toronto Area. It is also an attempt to emphasize the reality of spousal abuse among this population of women in the Canadian context, which has not yet been a major area of interest for researchers.

When I was in elementary school, I had heard family friends tell my father that, shortly after my aunt's arrival in Canada in the mid-90s, her husband had been physically abusing her. When my father would ask her if what he had been told was true, my aunt would deny being in an abusive marriage. She continued to remain silent until her situation became unbearable. One day, I answered the phone, my aunt was crying and she said, "Tell your father to pick us up!” My father later arrived home with my aunt and cousins, accompanied by their bags. That evening was the first time my aunt opened up to us about the abuse she had been experiencing. As I got older I was able to ask her questions and allowed her to tell me as much or as little as she wanted. Her first words to me were, "I have not told the family because when I tell people, they tell me to leave. It is not easy. I have children.” The more she spoke about her pain, the more I learned that spousal abuse is quite common within the Ghanaian community. Little did I know that over a decade later, my aunt's story would influence my decision to study this topic in graduate school.

The following will be a review of the literature which has been divided into two sections. The first section will focus on how spousal abuse is not only a global issue but a health issue as well. The second section focuses on help-seeking in relation to spousal abuse and mental health. 


\section{Literature Review}

\section{Spousal Abuse: A Global and Health Issue}

Definitions are important to every aspect of understanding the phenomenon of spousal abuse. However, it is unlikely that current definitions detect the full nature and scope of immigrant women's experiences of spousal abuse (White, Yuan, Cook, \& Abbey, 2013). Still, throughout almost all of the literature examined, spousal abuse is recognized as a significant social and public health concern, especially for women (Ahmad, Ali, \& Stewart, 2005). As defined by Krug and World Health Organization (2002), spousal abuse is when a husband or wife uses intentional "physical force or power, threatened or actual that either results in or has a high likelihood of resulting in injury, death, psychological harm, or deprivation" (p. 4). The definition also includes intimidation and threats, as well as neglect that compromises the wellbeing of individuals and families (Krug \& World Health Organization, 2002). Furthermore, Paulino (2016) suggests that spousal abuse involves coercive and abusive behaviours that are used to establish and maintain power and control over a spouse, including the use of male privilege.

According to Hyman, Forte, Du Mont, Romans, \& Cohen (2006b), worldwide, spousal abuse has been identified as both a major public health and human rights problem, and both acute and chronic health problems are associated with spousal abuse. Previous research has suggested that the general health status of women who experience spousal abuse is poorer as a result of harmful health outcomes (Ogunsiji, Wilkes, Jackson, \& Peters, 2011). There is also an increased risk for suicidal behaviour, and an increase in chronic health issues (Ogunsiji et al., 2011). In addition to physical injuries, ongoing anxiety and depression, autonomy that has been reduced, diminished productivity and participation in social activities, as well as a reduction in 
taking care for self and family, experiencing sexual and gynaecological problems, and adverse outcomes of pregnancy add to the list of reduced health outcomes (Hyman et al., 2006b; Ogunsiji et al., 2011). Riger, Ahrens, and Blickenstaff, 2000 (as cited in White et al., 2013) explain that passive acts of aggression, in which perpetrators intend to cause harm by omission is rarely included in research that focuses on spousal abuse. An example of such behaviour is the perpetrators failure to provide childcare when promised, which can result in loss of work or income for the woman who has been abused (Riger et al., 2000 as cited in White et al., 2013).

Ogunsiji et al. (2011) reported in a study of 18 West African women in Australia that the women considered the types of abusive behaviours that they had experienced (emotional and financial manipulation, bullying and verbal abuse, being silenced during family discussions, and physical abuse) as something that is to be kept in the private domain. As said by the women, family finances and all other aspects of the women's lives were controlled by their husbands (Ogunsiji et al., 2011). Participants felt they had little agency over their lives and experienced this subordination in silence. They were also reminded and given the justification on multiple occasions by their husbands that he has the right to dominate family decisions as the man of the house. Also, most of the women had immigrated to Australia as spouses of their husbands, and felt intimidated even more about taking action against their husbands (Ogunsiji et al., 2011).

\section{Help-Seeking: Spousal Abuse and Mental Health}

Literature suggests that help-seeking and the process of self-disclosure are connected.

The risks associated with self-disclosure can contribute to the avoidance of seeking professional help. Given that seeking professional help is not an easy task, psychologists can assist women experiencing spousal abuse through the use of interventions that are specifically focused on seeking help (Vogel \& Wade, 2009). This may involve making women feel a sense of comfort 
and empowerment to disclose what they are going through without the fear of social isolation. A study on the well-being among Black African immigrant women living in the United States noted the challenges women experienced in seeking help for mental health, consequences of spousal abuse: "Back home, people who are mad, they're outcast. And nobody wants to reveal any depression they are going through and I think [it's] because they're afraid it's going to be considered madness" (Sellers, Ward, \& Pate, 2006, p. 52). Additionally, another woman explained that "African people don't actually come out to say depression as such, but most of the ailment or most of the complaints all kind of stem from depression" (Sellers et al., 2006, p. 52). In addition Beydoun, Beydoun, Kaufman, Lo, \& Zonderman (2012) state that people suffering from spousal abuse are at a greater risk of developing depression.

For most Canadian women, both immigrant and non-immigrant, findings suggest that spousal abuse continues to remain a hidden issue (Hyman et al., 2006b). Among immigrant women, limited research has been conducted on help-seeking (Hyman et al., 2006b). Data has consistently shown that Canadian immigrant women underutilize legal and medical services, telephone hotlines, and shelters, in comparison to women in the majority population who have been abused (Hyman et al., 2006b). To add, eight percent of women in Canada who were living with a common-law partner or were married had experienced sexual or physical abuse, and nearly 20 percent (19.6\%) had experienced financial and emotional abuse by a current or former partner at least once during the five years preceding the 1999 General Social Survey (GSS) (Hyman, Forte, Du Mont, Romans, \& Cohen, 2006a). The same data set was used by other researchers and they had found that compared with women who were born in Canada, significantly lower rates of spousal abuse were reported by immigrant women in Canada (Hyman et al., 2006a). O'Grady (2011) states that calling the police may trigger an immediate physical 
assault and for fear of retaliation, women who are in intimate relationships may not call the police.

Immigrant woman may also have other reasons for staying silent when it comes to dealing with the challenges of abuse such as, the fear that their husbands can be arrested, thereby leaving them as the sole caregivers of their children (Ogunsiji et al., 2011). Ogunsiji et al. (2011) explain that this fear continued to keep West African women silent when it comes to their experiences of spousal abuse. The authors further noted the women's reluctance to report their experiences of abuse might be because of their limited integration into mainstream society. The West African immigrant women who were integrated believed that spousal abuse should be openly discouraged and reported.

\section{Historical Context of Ghanaian Immigration to Canada}

This section will consist of a brief summary of the history of Ghanaian immigration to Canada, as it will not be feasible to comprehensively recount the historical details that have occurred. By no means is the conciseness of this section a way to undermine the historical events that took place.

Ghanaian people have been immigrating to Canada in small numbers since the 1960s (Wong, 2000). However, there has been an increasing level of emigration from Ghana to Canada since the early 1980s (Wong, 2000). Wong (2000) states that since the 1970s, the economy of Ghana has undergone a crisis of stagnation, which resulted in average wages declining, as well as economic and social standards of living declining overall. This explains the increased amount of Ghanaians emigrating from the country in the early 1980s. Moreover, policies implemented under the Structural Adjustment Program (SAP) resulted in civil and state workers being cut 
down, severe cutbacks in health care and other social services, and an increase in unemployment (Wong, 2000). Such stringent measures caused further deterioration of the economy (Wong, 2000). Additionally, the wave of immigrants that arrived from Ghana to Canada in the 1980s was diverse in gender and class (Donkor, 2005). Different from the group that arrived in the late 1970s which was mainly comprised of male students, the group that arrived to Canada in the 1980s were seeking job opportunities and women were prominently featured in this wave of migration, unlike the Ghanaians who arrived in the late 1970s (Donkor, 2005).

In the middle of the economic crisis in Ghana, conflict and political instability plagued the country (Wong, 2000).Under the ruling military regime of Flight Lieutenant Jerry John Rawlings, who was later elected the President of Ghana, there were rampant occurrences of human right abuses which included harassment, false imprisonment, repression of political opinions, murders, and seizures of property (Wong, 2000). The volatile political situation and the declining employment opportunities spurred Ghanaians to go to other countries, as some were seeking political freedom while others were pursuing economic prosperity (Wong, 2000).

Within the Greater Toronto Area, Ghanaian immigrants live in different residential areas, which include cities such as Toronto, York, East York, North York, Etobicoke, Scarborough, and the suburbs of Brampton and Mississauga (Owusu, 1999). Data from the 2006 Census of Population indicates that at the time of the census, approximately $63 \%(14,720)$ of the 23,220 Ghanaian immigrant residents in Canada were in the Toronto area (Akosah-Sarpong, 2006 as cited in Kuuire, Arku, Luginaah, Buzzelli, \& Abada, 2016). Census data in 2016 has shown that 7.5 million people born outside of Canada came to the country through the immigration process. According to the 2016 Census, over 200 places of birth were reported by immigrants in Canada. During this time, the foreign-born population represented more than 1 in 5 people (Statistics 
Canada, 2017). Of the 200 countries, there were approximately 10,001 to 100,000 immigrants in Canada from 64 countries, one of which is Ghana (Statistics Canada, 2017). This data indicates that the Ghanaian population in Canada is continuing to grow.

\section{Conceptual Framework}

\section{"I never knew how strong I was until I lived through this." - Laako}

Cohen (2017) states that resilience is how well a person can adapt to the events in their life when faced with adversity. The American Psychological Association (2018) defines resilience as "the process of adapting well in the face of adversity, trauma, tragedy, threats or significant sources of stress such as, family and relationship problems, serious health problems, or workplace and financial stressors." Tsirigotis and Łuczak (2018) conceptualize resilience as a set of personality characteristics, along with skills and competences, which contribute to coping with trauma, stress, adversities and problems in life. They further state that resilience can be understood as one of the psychological resources that enables someone to cope with a difficult and/or extremely stressful situation (Tsirigotis \& Luczak, 2018). These interpretations of resiliency essentially describe resilience as one's ability to "bounce back" from difficult experiences (American Psychological Association, 2018).

However, the use of the words "bounce back" may suggest that resiliency enables one to recover from their issues almost instantaneously, which may not always be the case. The American Psychological Association (2018) explains that being resilient involves thoughts, behaviours, and actions that can be learned and developed. Therefore, it does not mean that a resilient person does not feel the intensity of the problem or event (Cohen, 2017) because according to the American Psychological Association (2018), there is a likelihood that resilience involves considerable emotional distress. Developing resilience is not always an individual 
process, nor does it have to be. It is important that we create environments where people can be resilient and women who are abused can access services. Families, friends, and communities can also create resilience in different ways one of which is by providing support and cultivating a stigma-free environment where people, specifically in immigrant communities, regardless of one's gender identity, sexual orientation, age, race, ethnicity, class, and religious beliefs can feel safe to share the hardships in their lives without fear and judgement. By regularly communicating the message in our communities that it is okay to seek help for abuse and mental health, it can be a small yet impactful step forward towards decreasing the number of people who suffer in silence from these issues. My research question is, how do women of Ghanaian origin who are living in the Greater Toronto Area cope with spousal abuse? The method used to conduct this study is described in the following section of this paper.

\section{Method}

\section{Sample and Data Collection}

A qualitative research approach was used for this study because of the limited knowledge that is available on Ghanaian women in the Greater Toronto Area about their experiences of spousal abuse and the exploratory nature of my research, More specifically, an interpretive approach of phenomenological research was used for this study because it allowed me to gather descriptive, in-depth information about each woman's lived experiences of coping with abuse, while also disclosing the content and meaning of the behaviours that were unique to their lives (Ting, 2010).

According to Blackstone (2014), purposive sampling may be used "when a researcher wishes to include only people who meet very narrow or specific criteria" (p. 80). In my study, purposive sampling was used to include women of Ghanaian origin living in the GTA, over the 
age of 18 years, who have experienced spousal abuse, are a permanent resident of Canada or a Canadian citizen, had been married and lived with their spouse in Canada at the time the abuse had occurred, and are willing to be interviewed for research purposes. This was my eligibility criteria.

After receiving ethical approval from Ryerson University’s Research Ethics Board, participant recruitment posters were placed in community centres, places of worship, event halls, and Ghanaian grocery and retail stores across the GTA, after obtaining verbal permission from church leaders and the owners/managers of these establishments. Verbal permission was an acceptable form of approval, as it is common in the Ghanaian community for flyers, posters, and advertisements to be posted in such locations whenever necessary. Participants were free to contact me at their convenience. When contacted, I ensured that they met my eligibility criteria and when interest to participate in my study was expressed, I asked the women to tell me what would be the safest way for me to contact them in order to set up a meeting in-person to review and sign the consent form and to conduct the interview. Each woman subsequently provided me with their contact information.

The participants' right to withdraw from participation was clearly stated in the consent form, but it was also verbally reiterated at the time of each interview session. If any participant decided to withdraw from participating in my research study during or after the interview, a reason for withdrawal was not required. Participants were given the opportunity to reconsider their participation within one week of being interviewed to ensure timely completion of this paper. Any participant who decided to withdraw, would have their data entirely expunged from the audio recorder and interview transcript. After explaining the potential risks of the study, confidentiality, honorarium $(\$ 30)$, voluntary nature of the study, and the right to withdraw, as 
well as answering all questions and clarifying any misunderstandings, 18 women signed the consent form. When interviews were about to take place, eight women voluntarily withdrew their consent despite being assured that confidentiality will be kept. Nonetheless, 10 women between the ages of 37 and 63 years completed the interview individually.

Before each interview began, I asked the women what language they would feel most comfortable speaking. Although the participants spoke different Ghanaian dialects, all of the interviews were spoken in English. Every participant was given a list of support services prior to the start of the interview due to the possibility of experiencing distress during the interview. Each woman was also given the opportunity to create a pseudonym for herself, by which they were referred to in interview transcripts and in this paper. The demographic information of each participant was also collected with the intention of further elucidating the level of social networks participant's may have access to, especially the formal social support they may already have access to or they might need in addressing spousal abuse.

The interviews were semi-structured which allowed the use of follow-up probing questions, and were audio-recorded with the participants' consent, and transcribed verbatim afterwards for analysis. The audio-recording of every interview was deleted after the interviews were transcribed. The women were asked open-ended questions such as, "What can you tell me about the nature of the abuse you experienced?, "What can you tell me about the hardships you may have experienced?", "What impact did experiencing spousal abuse have on your life?", "What options did you have in dealing with what you went through?", "What or who helped you get through your situation?", and "What or who would have been helpful to you?" In order to ensure aural and visual privacy for the interviews, each interview took place separately, on a different day, at a public library with access to a closed-door room, which I booked in advance to 
guarantee availability. When two participants asked for the interview to occur in their home, I explained to them that an interview conducted in a closed-door room at a public library is public enough to ensure privacy, but also safe enough for both the participant and I. Whereas in their home, there could be someone who is there reporting to their husband (if she is still married to him) or other family members about the interview. Her husband may even walk-in, which could create issues or put her in an unwanted situation. I also gave the same explanation to the participants who did not request for the interview to take place in their home to ensure that they understand why I chose the interview location. After the explanation, the women were understanding of the chosen interview location and felt comfortable with where the interview will be conducted. For time spent in order to be available to take part in this study, along with travel costs that participants may have incurred, every participant was given an honorarium of $\$ 30$ cash.

\section{Trustworthiness}

Recruiting participants in the way that was described in the Method section of this paper, avoided the researcher from having a conflict of interest with the participants. All of the findings were reported in this paper to prevent introducing bias into the study and misrepresenting the data. Furthermore, giving participants the opportunity to inform the researcher of what language they preferred to speak during their interview, allowed them to express themselves clearly without influence from the researcher. Notes that included non-verbal cues and gestures were taken during and after each interview as part of an audit trail (Ting, 2010). By using direct quotes from the transcripts, the reader can engage in a reflection process about how the data has been used in order to generate the major themes in the findings (Ogunsiji et al., 2011). The use of 
open-ended questions during the interviews, allowed participants to tell their stories authentically.

\section{Analysis}

In the interpretive phenomenology method of research, a phenomenon (an experience or reality) that can be described as people live through the experience is identified by the researcher (Ivey, 2013). The researcher has individuals speak about the experience and also describe the experience as they go through it (Ivey, 2013). Ivey (2013) states that the focus of data collection using this method involves the participant's exact words and expressions. Essentially, the value of interpretive phenomenology according to Ivey (2013), is that it gives insight into an experience that is not understood. With regard to reporting findings of the research, themes are identified and statements from either the participant or a summarization of the statements by the researcher are provided to support the themes (Ivey, 2013).

The initial stage of analysis for my study consisted of thoroughly reading through the transcripts of the interviews. The data were then coded into themes with headings and classifications that reflected the original matter of enquiry, as well as any new themes emerging from a reading of the transcripts. Notes taken of the non-verbal cues and gestures were useful in assisting with the accurate contextualization of the participants' stories (Ogunsiji et al., 2011). The resilience framework shaped the researcher's analysis of the study by having a conceptual understanding of spousal abuse as it relates to the experiences of Ghanaian immigrant women in the GTA

The findings from the study are detailed in the following section. Quotes from the participants are also included to provide context and give added emphasis to the themes. 
Moreover, pseudonyms chosen by the participants themselves have been used to maintain confidentiality.

\section{Results}

When the interviews took place, five (50\%) participants between 37 and 49 years of age reported being currently married to their husband. Three (30\%) participants between 51 and 59 years of age were separated, divorced, or widowed. While 2 (20\%) participants between 61 and 63 years of age were divorced or widowed. It must be noted that all were married at the time of when the abuse was experienced. Also, although all women reported their current immigration status as being Canadian citizens, at the time of abuse, most women were permanent residents of Canada. Participants had immigrated to Ontario between 1977 and 2004. The participants' length of marriage ranged from 12 to 39 years. At time of the interviews they were residing in North York, Etobicoke, and Scarborough, and were employed on a full-time basis. Participants' highest level of education ranged from having a secondary school diploma or the equivalent to a Bachelor's degree. See Appendices A, B, and C.

Analysis of each transcribed interview revealed that many women experienced physical abuse, but some women also endured a combination of verbal, and emotional abuse through name-calling and insults, threats, blame, belittling, humiliation, control, and stalking. The occurrences of abuse led to some women lying about their experiences in order to conceal the truth from their co-workers.

Trust issues and a shift in personality (such as no longer being extroverted) were reported as well. While some women reported not having any friends to talk to at the time, other women reported being withdrawn from their friends as a result of the abuse. 
Four themes have been identified: Children and Faith in God, Working to Survive, Working to Cope, Suffering in Silence: Lack of/Limited Support, and The Stigma of Mental Illness and Seeking Help.

\section{Children and Faith in God}

Most women reported not having any "outside support" and having to rely on themselves to get through the hardships of life arising out of the abusive experiences, while some women found strength through their faith in God and/or in putting their children's needs before their own.

Analysis of the transcribed interviews revealed that for the participants who had children, their children helped them get through their difficult times, as did their faith in God.

If I had someone to talk to, it would have made my life a little bit easier to live. All I needed was someone to tell me that it would be okay, but I had God and I prayed to God every day. I leaned on Him... Even though they [children] were young and did not understand what was going on, I had to be strong for them. It was really hard, very hard. I thought my children will grow up without their mother, but I got through it by the grace of God. Amen! - Adjoyoo

If it were not for the Lord, I don't even know how I could have got through. - Esi

Regarding whether the women decided to stay in their marriage or leave, participants said:

I can't begin to tell you how many times I have thought of leaving. Maybe, just maybe if I left sooner I would have been a mom. By leaving, I thought I would have the family that I have always wanted to have... give my parents grandchildren... but by the time I left, it was too late. - Kabuki

Leave? Leave and go where? I thought about it many times, but I had nowhere to go. You don't just leave. You need to have a plan and I didn't have that. I had no plan and nowhere to go. In life when you have children, things are different. If I did not have a child, maybe I would have left. People say "leave, leave." It is easier said than done. - Dede

After being told that she stayed in her marriage, Dede was asked, "What made you stay?" She explained that her daughter was the reason for staying and despite his abusive behaviour 
towards her [the participant], her husband was a good father. Another woman reported that her involvement in the church, her faith in God, and her children, helped her cope:

My involvement in the church saved me... but I still kept my problems at home to myself. No one at church knew... I stayed because God told me that it would get better. God was right because eventually things got better, not perfect, but better... It was still hard on me and at times I ask myself "why did I stay?" Then I remember my kids. - Esi

\section{Working to Survive, Working to Cope}

Several participants reported being financially dependent on their spouse until they were able to obtain work or become self-employed. Esi describes the hardships she went through as she coped with living through spousal abuse:

I told my sister back home [about the abuse] but she was helpless. In Canada, I was alone and because I was not working at the time it was very hard to have my own money. I had to depend on him, so I learned to cope as best as I could under the circumstance that I was in. - Esi

When the women were asked whether there was anyone or anything that helped them through their situation or what their options were in dealing with what they went through, some of the participants reported working as a way to cope with their experiences of spousal abuse.

After being financially dependent on her husband for many years, Akusika explains the difficulty she experienced of having to work after her separation:

At the time [of the abuse] I wasn't working. He supported me financially. But, after the separation I started working at . This gave me some independence and a sense of purpose... I helped myself. It was hard from the beginning to push myself to get a job but I knew I had to work to support myself. I got a job and during that time it helped me get through. Still, it was not easy... but it helped. - Akusika

Further examples of participants who used work as a way to cope with spousal abuse:

Before I started to work, I did not have options. I mean, I could have told my parents and went back home [to Ghana] but I chose to work... I would work overtime to keep me busy because I didn't want to go home. I couldn't call that apartment home. This went on for about two years. - Abena 
My only option at the time... to work. I had to work to stay alive. - Maku

\section{Suffering in Silence: Lack of/Limited Support}

Throughout the interviews, most of the women's stories revealed not having a support system, and therefore relying on themselves to cope.

What I went through, no one knew. I kept everything to myself. When you are married, you should be able to go to your husband for support. But when your husband is the one who is causing you pain, abuse, and suffering, how do you go to him? - Adjoyoo

I lied about my abuse. Nobody knows. I kept it to myself... These support services that you gave me... I didn't know this was available. I didn't tell anyone, maybe if I did, I would have known where to go. - Dede

Where do I go with my three children when I had nowhere to go and no one to go to or even talk to for that matter. - Laako

Although the majority of women reported keeping the abuse to themselves, some women reported breaking their silence after suffering in silence alone for a long period of time. One woman reported her friend as being her support system, while two women reported their brothers, who also live in the GTA, as being the only support they had:

It bothered me that my plans of how I thought things would have been did not go how I planned. But it could have been worse if my brother was not here. - Kadi

He [husband] used my money to buy alcohol. When he would get drunk that is when he would become violent, physically, and emotionally. At work, I had to lie about what happened to me... I wanted to tell my co-workers but he warned me not to tell anyone. I was afraid he would find out, so I just suffered in silence... My brother let me move in with him after I told him everything and he said to me-I will not forget these words, "What took you so long?" - Maku

A participant disclosed the ways in which the abuse silenced her. Talking about the abuse she experienced had a negative effect on her health: 
Two words: Alone and ashamed. It affected me in a way that everything changed. I used to go out often, but I became withdrawn from my friends. I started to gain a lot of weight too. My performance at work was declining and it was noticeable to everyone, but I still kept it to myself. Keeping it silent was affecting me negatively. - Awisi

Women who reported being abused to the police, did not see a decline in the abuse. The abuse increased and reporting it to the police actually silenced them because their spouse knew that they were being reported.

At first my option was to leave, but then if I left where would I stay? Then my next option was to call the police but it made [husband] angry [the first time abuse was reported] so I learned to keep my problems to myself. I didn't know of the shelters or services. - Akusika

\section{The Stigma of Mental Illness and Seeking Help}

Analysis of the women's transcribed interviews revealed that for some, spousal abuse contributed to their diagnosis of depression. Many participants also reported the loneliness and stress they experienced from adjusting to their new lives in Canada, which was also a contributing factor for depression as one participant mentions:

I was admitted into the hospital two times because of stress and depression. Adapting to life in Canada was hard on me. I also had children within a short period of time and caring for them is mostly on me because he [husband] barely comes home and when he does, he doesn't help and we just fight. Even when I was in the hospital, I had to hire a babysitter to take care of my kids. I felt like a single mother... If I had a support system that would have been helpful. I was lonely and depressed... When you are new to a country and your family is back home, you are not aware of all the services available. But also back then in Canada, abuse and even mental health were not openly talked about as it is now. I was married but alone. - Adjoyoo

For another participant, her experience had an effect on both her mental and physical health:

He started to blame me for him losing his job. He started telling me what to do and how to do it. Keeping up with everything became unbearable because he wasn't my child, he was my husband. I couldn't handle this life... It was taking a toll on my mind. I was stressed out to the point where my period had stopped. When I went to the doctor I was told that I had depression. He asked me if I wanted to go to a therapist and I rejected his offer because I didn't want anyone to think I am crazy. - Kabuki 
Later in the interview, Kabuki stated that her inability to afford therapy sessions was another reason for declining her doctor's suggestion to see a therapist.

The stigma of mental illness is in every community but more so in racialized and marginalized communities because people in these communities also deal with a range of issues that marginalize them (Guruge, personal communication, January 31, 2017). Not only do the interviews exemplify the stigma of mental illness, but they also illustrate the stigma of seeking help. Limitations of the study are stated in the following section.

\section{Limitations of the Study}

A limitation of this study is the small sample size, due to the time constraints of completing this Major Research Paper. Interviews may have been more enriching if additional Ghanaian immigrant women participated. Also limited by the small sample size of the participants, is the ability to generalize the findings in this paper to the larger Ghanaian population of women in the Greater Toronto Area who may have also experienced spousal abuse. A mixed methods research approach using instruments measuring resilience could be utilized in the future, although unused in this study.

\section{Discussion}

Despite the use of the term depression in this paper, it does not suggest nor is it labelling all Ghanaian women who have experienced spousal abuse as having depression. Use of the term in the Results section reports the findings of the study in relation to the participants who reported having been diagnosed with depression by a licensed medical practitioner in Canada.

The English language is Ghana's official language, which is commonly spoken by many people in Ghana, predominately by those who received an education. Demographic information from participants in the study indicate the levels of education they have completed (see 
Appendix B). Their proficiency in English allowed the participants to communicate effectively during the interviews.

What is unique about this study is that this is the first known qualitative research conducted on spousal abuse, specific to Ghanaian immigrant women living in the Greater Toronto Area and their experiences. What is not unique, is the silence that exists in immigrant communities when spousal abuse is involved. This study confirmed the association between spousal abuse and depression, as well as the stigma of mental health and help-seeking.

Although, not every participant in this study is a mother, the stories of the women express the difficulty many immigrant women with children face when living with an abusive husband. Also, the participants' interviews emphasize both the significance of their faith in God and the use of employment as coping strategies. On the other hand, keeping the abuse to themselves was another way most of the participants coped with their experiences. The study also found that some of the women were financially dependent on their husbands. According to Kaur and Garg (2008), economic dependence is the central reason women stay in abusive relationships. Not having an alternative place to go was another reason participants stayed. According to RogersSirin, Ryce, and Sirin (2013), immigration is a cultural transition that is life changing and it involves dealing with a range of challenges that can have implications on one's mental health. Findings from the study revealed that experiencing spousal abuse as an immigrant in a foreign country can also lead to issues of mental health such as depression. It can also contribute to the mental health issues that one may already have as a result of acculturative stress. In addition, some participants did not seek formal support or counselling services due to the fear of not being believed, not feeling safe, and a lack of awareness of available services. 
Typically, the decision to seek professional help is not an easy one (Vogel \& Wade, 2009) especially in immigrant communities. Lee (1989) explains that there are barriers to seeking help, which includes a lack of information about available services and the skills that are needed to access these services. Ontario Council of Agencies Serving Immigrants (2017b) states that one of the reasons that keep women unaware of support services is not being informed about such services at ports of entry into Canada. Outreach material created by organizations may also be inaccessible to some women due to the format they are created in (Ontario Council of Agencies Serving Immigrants, 2017b). For outreach material that are accessible online or through mobile applications, immigrant women who are not familiar with the use of technology may not know that there are resources available. Conversely, it can be argued that a librarian at a public library can be of assistance. However, it must be considered that someone who is going through spousal abuse may not want to disclose this information to a stranger.

Furthermore, service delivery for racialized and gendered immigrants requires culturally appropriate services. Since no culture is homogenous, it is presumptuous and problematic to assume that what one client attributes to their culture, another client will also, as this can inadvertently perpetuate racism and reinforce stereotypes (Ontario Council of Agencies Serving Immigrants, 2017a). Thus, service delivery for immigrant women should not be a "one size fits all" approach. To this day, despite the many years that have passed since the participants have experienced spousal abuse, some women reported the effects of their trauma as ongoing and are still coping, though, the specifics of their current coping methods were not revealed. 


\section{Recommendations}

The findings suggest that Ghanaian women may benefit from the use of formal support and counselling services. Also, since the Ghanaian women living in the Greater Toronto Area who have experienced spousal abuse are predominately silent on the issue, a response to this is forming a support group for Ghanaian women, which I would name, Ghanaian Women

Overcoming Spousal Abuse. Bi-weekly meetings could take place in a setting that the women are familiar with and are likely to feel safe. This can include a church or a private room in a community centre. Furthermore, this group may serve as an outlet for the women to share their stories with other Ghanaian women who can understand and relate to their lived experiences. Though it will take time for the women to feel comfortable discussing their experiences with settlement workers, counsellors, and/or health practitioners, the gradual progress that they make throughout the support group may allow each individual woman to gradually transition into utilizing the formal support and counselling services that are currently available in the GTA.

Also, findings from this study indicate that the lack of awareness of existing available services was a barrier towards seeking help. To address this issue, when immigrants arrive in the Greater Toronto Area they should be given a guide, similar to the City of Toronto's Welcome Home: A Guide to Services for Tenants. This guide contains over one hundred pages of useful information about a range of services in Toronto, contact information included. If this becomes a standard practice that is implemented at airports across the GTA, it can provide an immigrant who is experiencing spousal abuse with safe alternatives and more options with regard to coping strategies and seeking help.

It is important that a person who is in an abusive relationship has someone who they can trust to support them. The person who is being abused may not establish a conversation 
immediately, if at all. Creating a safe and non-judgemental environment where a conversation can be had may be helpful. The behaviour of an abusive spouse cannot be controlled, but offering assistance to create a safety plan in case of an emergency can help to increase one's own safety and well-being. Letting the individual know that help is available may assure them that they are not alone. Above all, it is important that the individual is listened to and taken seriously without making assumptions, generalizations, minimizing their feelings or their experience(s).

\section{Conclusion}

This research has shown the impact spousal abuse has on Ghanaian women in Greater Toronto Area, their coping strategies, and the importance of accessing and utilizing formal support and counselling services when it comes to coping with the effects of spousal abuse. The women in the study displayed resilience through their ability to not allow their experiences to hinder them from continuing to live their lives (or rebuild it), to work, or take care of their children. Despite the predominate use of silence as a coping strategy for spousal abuse, the women's resilience enabled them to muddle through their experiences as best as they knew how to.

By participating in this study, not only can the women's contributions to this research be used to improve service delivery for this population of women, but it can also educate, encourage, and empower other Ghanaian women in the GTA who have experienced spousal abuse. The new knowledge that has been generated through the researcher's positionality in the study (see Prologue) and the intersectional nature of the study is likely to add value to scholarly work in the future.

As a community, efforts towards destigmatizing violence against women and mental health can help to facilitate the use of formal support and counselling services, especially when it 
comes to Ghanaian women making progress towards speaking openly in a professional setting about their experiences. Since the experiences faced by the participants in this study is not representative of all Ghanaian women who may have experienced spousal abuse in the Greater Toronto Area, further research is needed using a larger sample size. 


\section{APPENDIX A}

Table 1.1: Sample Demographics

Number of Participants by Age Group

\begin{tabular}{|c|c|c|c|}
\hline Gender & $37-49$ & $51-59$ & $61-63$ \\
\hline Female & 5 & 3 & 2 \\
\hline \multicolumn{4}{|c|}{ Current Marital Status } \\
\hline Married & 5 & & \\
\hline Separated & & 1 & \\
\hline Divorced & & 1 & 1 \\
\hline Widowed & & 1 & 1 \\
\hline \multicolumn{4}{|c|}{ Citizenship/Immigration Status } \\
\hline Canadian Citizen & 5 & 3 & 2 \\
\hline \multicolumn{4}{|l|}{$\begin{array}{l}\text { Length of Marriage } \\
\text { (in years) }\end{array}$} \\
\hline $12-15$ & 2 & & \\
\hline $20-23$ & 2 & & \\
\hline $25-29$ & 1 & 1 & \\
\hline $30-35$ & & 2 & \\
\hline $37-39$ & & & 2 \\
\hline \multicolumn{4}{|l|}{$\begin{array}{l}\text { Arrival to Canada } \\
\text { (in years) }\end{array}$} \\
\hline 1977-1979 & & & 2 \\
\hline 1982-1987 & & 2 & \\
\hline 1988-1992 & 1 & 1 & \\
\hline 1993-1997 & 2 & & \\
\hline $2002-2004$ & 2 & & \\
\hline
\end{tabular}


APPENDIX B

Table 1.2: Sample Demographics

Number of Participants by Age Group

\begin{tabular}{|c|c|c|c|}
\hline $\begin{array}{l}\text { Arrival to Canada } \\
\text { (province) }\end{array}$ & $37-49$ & 51-59 & $61-63$ \\
\hline Ontario & 5 & 3 & 2 \\
\hline \multicolumn{4}{|l|}{ Current Area of Residence } \\
\hline North York & 2 & 1 & 2 \\
\hline Etobicoke & 1 & 2 & \\
\hline Scarborough & 2 & & \\
\hline \multicolumn{4}{|l|}{$\begin{array}{c}\text { Highest Level of Education } \\
\text { Completed }\end{array}$} \\
\hline \multicolumn{4}{|l|}{ No schooling completed } \\
\hline \multicolumn{4}{|l|}{ Some primary school } \\
\hline \multicolumn{4}{|l|}{ Primary school } \\
\hline \multicolumn{4}{|l|}{ Some secondary school, no diploma } \\
\hline $\begin{array}{c}\text { Secondary school diploma or the } \\
\text { equivalent }\end{array}$ & 1 & & 1 \\
\hline \multicolumn{4}{|l|}{ Some college, no degree } \\
\hline College & 1 & 2 & \\
\hline Trade/technical/vocational training & 2 & 1 & 1 \\
\hline \multicolumn{4}{|l|}{ Some university, no degree } \\
\hline Bachelor's degree & 1 & & \\
\hline \multicolumn{4}{|l|}{ Master's degree } \\
\hline \multicolumn{4}{|l|}{ Professional degree } \\
\hline Doctorate degree & & & \\
\hline
\end{tabular}




\section{APPENDIX C}

Table 1.3: Sample Demographics

Number of Participants by Age Group

\begin{tabular}{|c|c|c|c|}
\hline Current Status of Employment & $\mathbf{3 7 - 4 9}$ & $\mathbf{5 1 - 5 9}$ & $\mathbf{6 1 - 6 3}$ \\
\hline Employed: Full-time & 5 & 3 & 2 \\
\hline Employed: Part-time & & & \\
\hline $\begin{array}{c}\text { Self-employed } \\
\text { employment }\end{array}$ & & & \\
\hline $\begin{array}{c}\text { Unemployed, seeking part-time } \\
\text { employment }\end{array}$ & & & \\
\hline $\begin{array}{c}\text { Unemployed, not seeking } \\
\text { employment }\end{array}$ & & & \\
\hline Homemaker & & & \\
\hline Student & & & \\
\hline Retired & & & \\
\hline Other & & \\
\hline
\end{tabular}




\section{References}

Ahmad, F., Ali, M., \& Stewart, D. E. (2005). Spousal-abuse among Canadian immigrant women. Journal of Immigrant Health, 7(4), 239-246. https://doi.org/10.1007/s10903-005-5120-4

American Psychological Association. (2018). What is resilience? Retrieved from http://www.apa.org/helpcenter/road-resilience.aspx

Baafi, A. A. A. (2010). Ghana: Domestic violence cases on the rise. Retrieved from AllAfrica website: https://allafrica.com/stories/201001250928.html

Beydoun, H. A., Beydoun, M. A., Kaufman, J. S., Lo, B., \& Zonderman, A. B. (2012). Intimate partner violence against adult women and its association with major depressive disorder, depressive symptoms and postpartum depression: A systematic review and meta-analysis. Social Science \& Medicine, 75(6), 959-975. http://dx.doi.org/10.1016/j.socscimed.2012.04.025

Blackstone, A. (2014). Principles of sociological inquiry: Qualitative and quantitative methods. Saylor Foundation, 1-183.

Cohen, H. (2017). What is resilience? Retrieved from https://psychcentral.com/lib/what-isresilience/

Donkor, M. (2005). Marching to the tune: Colonization, globalization, immigration, and the Ghanaian diaspora. Africa Today, 52(1), 27-44. http://dx.doi.org/10.1353/at.2005.0054

Hyman, I., Forte, T., Du Mont, J., Romans, S., \& Cohen, M. M. (2006a). The association between length of stay in Canada and intimate partner violence among immigrant women. Journal of Public Health, 96(4), 654-659.

http://dx.doi.org/10.2105/AJPH.2004.046409 
Hyman, I., Forte, T., Du Mont, J., Romans, S., \& Cohen, M. M. (2006b). Help-seeking rates for intimate partner violence (IPV) among Canadian immigrant women. Health Care for Women International, 27(8), 682-694. http://dx.doi.org/10.1080/07399330600817618

Ivey, J. (2013). Interpretive phenomenology. Pediatric Nursing, 39(1), 27.

Kaur, R., \& Garg, S. (2008). Addressing domestic violence against women: An unfinished agenda. Indian Journal of Community Medicine, 33(2), 73-76.

Krug, E. G., \& World Health Organization. (2002). World report on violence and health: Summary. Geneva: World Health Organization.

Kuuire, V. Z., Arku, G., Luginaah, I., Buzzelli, M., \& Abada, T. (2016). Transnationalismintegration nexus: Examining the relationship between transnational housing investment and homeownership status in Canada. Geoforum, 75, 168-179. https://doi.org/10.1016/j.geoforum.2016.07.010

Lee, C. (1989). The forgotten majority. Canadian Women Studies/Les Cahiers De La Femme, $10(1), 52-54$.

O'Grady, W. (2011). Crime in Canadian context: Debates and controversies (2nd ed.). Toronto, Canada: Oxford University Press.

Ogunsiji, O., Wilkes, L., Jackson, D., \& Peters, K. (2011). Suffering and smiling: West African immigrant women's experience of intimate partner violence. Journal of Clinical Nursing, 21, 1659-1665. http://dx.doi.org/10.1111/j.1365-2702.2011.03947.x

Ontario Council of Agencies Serving Immigrants. (2017a, June 14). Module 1: Framework for understanding sexual violence. Retrieved from Understanding and Responding to Sexual Violence in Immigrant and Refugee Communities (Facilitated) Group K [Online course] website: http://learnatwork.ca 
Ontario Council of Agencies Serving Immigrants. (2017b, June 21). Module 2: Realities of immigrants and refugee women. Retrieved from Understanding and Responding to Sexual Violence in Immigrant and Refugee Communities (Facilitated) Group K [Online course] website: http://learnatwork.ca

Owusu, T. Y. (1999). Residential patterns and housing choices of Ghanaian immigrants in Toronto, Canada. Housing Studies, 14(1), 77-97. https://doi.org/10.1080/02673039983019

Paulino, M. (2016). The different forms of spousal violence. In Forensic psychology of spousal violence (pp. 33-44). Cambridge, MA: Academic Press an imprint of Elsevier.

Rogers-Sirin, L., Ryce, P., \& Sirin, S. R. (2013). Acculturation, acculturative stress, and cultural mismatch and their influences on immigrant children and adolescents' well-being. In R. Dimitrova, M. Bender, \& F. V. D. Vijver (Eds.), Global perspectives on well-being in immigrant families (pp. 11-30). New York, NY: Springer. https://doi.org/10.1007/978-14614-9129-3_2

Selby, H. (2009). Ghana: Violence against women - an increasing pandemic. Retrieved from AllAfrica website: http://allafrica.com/stories/200912100532.html

Sellers, S. L., Ward, E. C., \& Pate, D. (2006). Dimensions of depression: A qualitative study of wellbeing among black African immigrant women. Qualitative Social Work, 5(1), 45-66. https://doi.org/10.1177/1473325006061538

Statistics Canada. (2017, October 25). Description: Immigrant population in canada, 2016 census of population. Retrieved from https://www150.statcan.gc.ca/n1/pub/11-627-m/11-627m2017028-eng.htm 
Ting, L. (2010). Out of Africa: Coping strategies of African immigrant women survivors of intimate partner violence. Health Care for Women International, 31(4), 345-364. https://doi.org/10.1080/07399330903348741

The World Bank. (2017). Community-based tools to prevent intimate partner violence. Retrieved from http://www.worldbank.org/en/programs/umbrellafacilityforgenderequality/brief/communi ty-based-tools-to-prevent-intimate-partner-violence

Tsirigotis, K., \& Łuczak, J. (2018). Resilience in women who experience domestic violence. Psychiatric Quarterly, 89(1), 201-211. https://doi.org/10.1007/s11126-017-9529-4

Vogel, D. L., \& Wade, N. G. (2009). Stigma and help-seeking. The Psychologist, 22(1), 20-23.

White, J. W., Yuan, N. P., Cook, S. L., \& Abbey, A. (2013). Ethnic minority women's experiences with intimate partner violence: Using community-based participatory research to ask the right questions. Sex Roles, 69, 226-236. http://dx.doi.org/10.1007/s11199-012-0237-0

Wong, M. (2000). Ghanaian women in Toronto's labour market: Negotiating gendered roles and transnational household strategies. Canadian Ethnic Studies, 32(2), 45-74. 